\begin{tabular}{|c|c|c|}
\hline Homepage: http://jusami.batan.go.id & Jurnal Sains Materi Indonesia & $\begin{array}{l}\text { Akreditasi LIPI } \\
\text { No.: 602/AU3/P2MI-LIPI/03/2015 } \\
\text { Tanggal 15 April 2015 } \\
\text { ISSN : 1411-1098 }\end{array}$ \\
\hline
\end{tabular}

\title{
KARAKTERISTIK HIDROGEL SELULOSA/POLIVINIL ALKOHOL UNTUK ABSORPSI LOGAM BERAT
}

\author{
Ambyah Suliwarno ${ }^{1}$ dan Prasetyo Bayu $\mathrm{Aji}^{2}$ \\ ${ }^{1}$ Pusat Aplikasi Isotop dan Radiasi (PAIR) - BATAN \\ Jl. Lebakbulus Raya No. 49, Jakarta Selatan \\ ${ }^{2}$ Sekolah Tinggi Manajemen Industri \\ Jl. Letjen Suprapto No. 26, Cempaka Putih Jakarta \\ E-mail :ambyahs@batan.go.id
}

Diterima: 5 September 2016

Diperbaiki: 19 Desember 2016

Disetujui: 5 Januari 2017

\begin{abstract}
ABSTRAK
KARATERISTIK HIDROGEL SELULOSA/POLIVINILALKOHOL UNTUK ABSORPSI LOGAM

BERAT. Dalam rangka pendayagunaan teknologi iradiasi serta pemanfaatan biomasa dan limbahnya, telah disintesis hidrogel selulosa/polivinil alkohol (selulosa/PVA) melalui kopolimerisasi dan ikatan silang hasil induksi iradiasi sinar- $\gamma$ pada dosis 10 dan $20 \mathrm{kGy}$. Hidrogel dengan total persen berat (b/b) sebesar $10 \%, 15 \%$ dan $20 \%$, tersusun dari PVA dan serbuk selulosa dari kayu jeunjing/sengon laut (albazia falcataria) ukuran partikel 40 mesh dengan masing-masing komposisi optimal. Dalam penggunaannya sebagai bahan absorben logam berat, hidrogel selulosa/PVA dikarakterisasi sifat fisik; fraksi gel dan persen pengembangan, serta morfologi permukaan dengan Scanning Electron Microscope (SEM). Pada percobaan ini, larutan ion logam Ag(I), Cu (II), dan Fe (II) pada konsentrasi masing-masing $1500 \mathrm{ppm}$, dengan variasi derajat keasaman $(\mathrm{pH})$ antara 2 hingga 7 dilakukan perendaman hidrogel selulosa/PVA hingga $24 \mathrm{jam}$. Sisa ion logam ditentukan dengan spektrofotometer serapan atom $(A A S)$ pada selang waktu tertentu. Hasil percobaan menunjukkan bahwa pada $\mathrm{pH}$ rendah, daya absorpsi hidrogel selulosa/PVA dari hasil optimal $(15 \%, 20 \mathrm{kGy})$ terhadap ion logam sangat kecil, dan meningkat dengan naiknya pH hingga 7. Hasil pengamatan menunjukkan penyerapan ion logam oleh hidrogel selulosa/PVA terjadi melalui pembentukan ikatan antara ion logam berat dengan gugus akrilat (khelat) dan mengikuti kinetika isothermal Langmuir pseudo orde-2.
\end{abstract}

Kata kunci: Hidrogel selulosa/PVA, Ion logam berat

\begin{abstract}
THE CARATERISTICS OF CELLULOSE/POLYVINYLALCOHOL HYDROGELS FOR HEAVY METAL ABSROPTION. In order to usability irradiation technology and the utilization of biomass and its waste, cellulose/polyvinyl alcohol (cellulose/PVA) hydrogels have been synthesized by copolymerization and crosslinking induced of $\gamma$-rays irradiation at the doses of 10 and $20 \mathrm{kGy}$. The hydrogels with total weight percent (w/w) of 10, 15 and 20\% respectively were composed of PVA and cellulose powder of falcata wood (albazia falcataria) with particle size of 40 mesh, within each blend optimum composition. In its designation as a heavy metal absorption material, the celluloce/PVA hydrogels are characterized by physical properties such as gel fraction, swelling behavior, as well as surface morphology with Scanning Electron Microscopy (SEM). For this experiment the metal ions solutions of $\mathrm{Ag}$ (I), Cu (II), and Fe (II) were prepared at the each concentration of $1500 \mathrm{ppm}$, with varying of acidity $(\mathrm{pH})$ between 2 to 7 , then celluloce/PVA hydrogels were immersed untill 24 hour. The remainder of metal ions is determined by an atomic absorption spectrophotometer (AAS). The experimental results shows that at low $\mathrm{pH}$, the metal absorption capacities of the celluloce/PVA hydrogels as optimal result $(15 \%, 20 \mathrm{kGy})$ are very small, and it was increased with increasing of the $\mathrm{pH}$ value until 7. The observed results indicate the absorption of metal ions by cellulose/PVA hydrogels from their interactions through the bonds formation between heavy metal ions and acrylic groups (chelates) and followed the Langmuir isotherm of pseudo-second order kinetic.
\end{abstract}

Keywords: Cellulose/PVA hydrogels, Heavy metal ions 


\section{PENDAHULUAN}

Pada akhir dekade ini, banyak peneliti di bidang lingkungan yang menaruh perhatian terhadap peran hidrogel dalam permasalahan pencemaran lingkungan, yaitu penyerapan ion logam berat dalam limbah cair atau larutan. Salah satu jenis hidrogel paling berpotensi sebagai absorben logam berat adalah PVA, yaitu polimer hidrofilik selain sifat kelarutannya dalam air, juga sifat biokompatibilitasnya serta daya swelling yang besar sehingga memberi peluang untuk diaplikasikan pada industri [1].

Logam berat didefinisikan sebagai semua logam yang bersifat racun, tanpa memperhatikan bobot massa atom. Pada tabel periodik, logam berat adalah logam transisi secara umum, seperti tembaga, timah, dan seng yang merupakan logam-logam penyebab dari pencemaran lingkungan dari sumber seperti bahan bakar bertimbal, limbah industri, ke dalam danau dan sungai oleh hujan asam [2]. Aplikasinya sebagai absorben logam berat, hidrogel selulosa/PVA dipandang sebagai absorben yang ramah lingkungan, dan merupakan campuran material yang saling memperkuat terhadap sifat fisiknya. Ikatan silang antar PVA dan juga PVA dengan selulosa akan memperkuat matrik hidrogel selulosa/PVA, sementara selulosa murni tidak bisa digunakan sebagai absorben karena hidrofilisitas dan sifat stabilitasnya [3].

Selulosa adalah polimer alam yang tersusun dari molekul cincin glukosa dengan rantai linear pada konformasi datar, mempunyai struktur kristal maupun amorf, ditemukan secara berlimpah dalam kayu dan lignoselulosa tanaman lainnya. Selulosa dengan unit monomer berulang $\left[\mathrm{C}_{6} \mathrm{H}_{10} \mathrm{O}_{5}\right]_{\mathrm{n}}$ terhubung oleh ikatan kovalen antara atom oksigen dengan atom $\mathrm{C}$ pertama pada cincin pertama, dan atom $\mathrm{C}$ ke 4 pada cincin kedua, sehingga disebut sebagai ikatan $\beta$ 1,4 glukosida. Adanya ikatan hidrogen dari gugus hidroksil pada cincin pertama dengan cincin kedua memberi efek pada kestabilan serta sifat fisik rantai selulosa dalam konformasi linier. Di alam, berat molekul selulosa bergantung sumbernya dan secara kimiawi mempunyai struktur (Gambar 1), dengan harga $\mathrm{n}$ antara 10.000 hingga 15.000 [4].

PVA merupakan serbuk berwarna putih, polimer sintetis dari senyawa organik yang larut dalam air, namun tidak larut dalam pelarut organik. Berdasarkan karakteristiknya, hidrogel PVA terbentuk monomer PVA (Gambar 2) melalui proses pengikatan silang,telah digunakan dalam berbagai aplikasi farmasi, biomedis serta industri. Ikatan silang tersebut bisa dilakukan baik secara kimia, fisika maupun dengan metode iradiasi sinar pengion yaitu sinar gamma dan berkas elektron $[5,6]$.

Pada penelitian ini daya swelling dari PVA pada poliblend hidrogel selulosa/PVA dipelajari interaksinya dengan beberapa ion logam dalam larutan. Ikatan silang dengan iradiasi merupakan metode yang sederhana, proses berlangsung pada suhu ruang serta tanpa

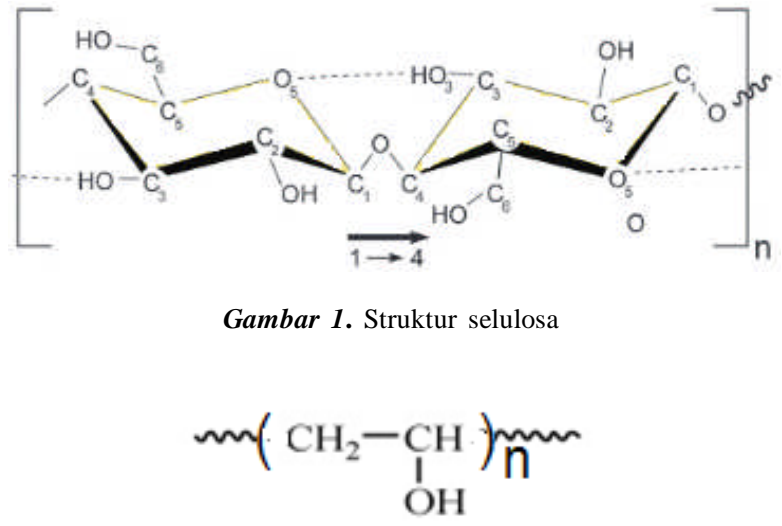

Gambar 2. Struktur poli (vinil) alkohol.

penambahan zat kimia lain, sehingga hasilnya bersih dari kontaminan. Melalui teknologi radiasi diharapkan dapat untuk memberikan nilai tambah khususnya biomasa serta limbahnya yang melimpah terdapat di wilayah Indonesia.

\section{METODE PERCOBAAN}

\section{Bahan dan Alat}

Serbuk serat selulosa terbuat dari kayu sengon (albazia falcataria) diperoleh dari Instansi Balai Besar Pulp dan Kertas Bandung, digunakan sebagai bahan pengisi dalam pembuatan poliblend hidrogel selulosa/PVA. Serbuk polivinil alkohol sebagai produk lokal yang diperoleh dari PT. Graha Jaya Pratama Kinerja, digunakan sebagai bahan utama campuran. Air suling bebas ion digunakan untuk pembuatan gel, pelarutan serta pengujian lainnya. Kristal $\mathrm{CuSO}_{4} 5 \mathrm{H}_{2} \mathrm{O}$, kristal $\mathrm{FeSO}_{4}$ $7 \mathrm{H}_{2} \mathrm{O}$ dan larutan $\mathrm{AgNO}_{3}$ digunakan sebagai larutan ion logam.

Peralatan yang digunakan dalam penelitian ini yaitu; iradiator IRKA dari sumber Co-60 digunakan untuk meradiasi sampel pasta, oven dengan kapasitas sampai dengan $200^{\circ} \mathrm{C}$ untuk pengeringan bahan serbuk selulosa dan sampel hidrogel.

\section{Cara Kerja}

Hidrogel selulosa/PVA dibuat dalam 3 konsentrasi dalam rasio berat (b/b) : 10\%, $15 \%$ dan $20 \%$. Larutan pasta diaduk hingga homogen sambil dipanaskan $80{ }^{\circ} \mathrm{C}$ selama 1 jam, dibuat secara duplo untuk variasi dosis radiasi. Pasta didiamkan hingga dingin pada suhu kamar, dan selanjutnya dicetak - tuang pada wadah dari plastik milar dengan ukuran $10 \mathrm{~cm} \times 6 \mathrm{~cm} \times 0,5 \mathrm{~cm}$, kemudian diradiasi dengan dosis 10 dan $20 \mathrm{kGy}$, akhirnya diperoleh hidrogel selulosa/PVA. Selanjutnya dikarakterisasi daya swelling, fraksi gel, morfologi material dan daya absorpsi terhadap ion-ion logam $\mathrm{Cu}, \mathrm{Ag}$ dan Fe. Di dalam matrik hidrogel terdapat material atau komponen yang terbentuk melalui ikatan silang dan bagian lain yang tidak berikatan 
silang. Komponen tidak berikatan silang akan terlarut dalam pelarut tertentu misalnya air, sedangkan yang berikatan silang tidak larut. Fraksi gel ditentukan dengan cara memotong hidrogel pada ukuran $1 \mathrm{~cm} \times 1 \mathrm{~cm}$, kemudian dikeringkan pada suhu $80{ }^{\circ} \mathrm{C}$ hingga berat konstan, dicatat sebagai $\mathrm{W}_{1}$. Potongan kering kemudian direndam dalam air suling selama $24 \mathrm{jam}$, residu disaring dan dikeringkan pada $80{ }^{\circ} \mathrm{C}$ hingga berat konstan dan ditimbang sebagai $\mathrm{W}_{2}$. Persen fraksi gel dihitung dengan Persamaan (1) [6,7]:

$$
\text { Persen gel }=\frac{\mathrm{W}_{1}-\mathrm{W}_{2}}{\mathrm{~W}_{1}} \times 100 \%
$$

Derajat swelling (\%DS) ditentukan dalam empat (4) waktu serapan air dalam sekali percobaan, pertama dibuat 4 sampel film gel dipotong dengan ukuran $1 \mathrm{~cm} \times 1 \mathrm{~cm}$, kemudian dikeringkan dalam oven pada suhu $60{ }^{\circ} \mathrm{C}$ hingga berat konstan, dicatat berat masing-masing sebagai $\mathrm{W}_{1}$. Setiap sampel direndam dalam gelas beker berisi $200 \mathrm{~mL}$ air suling pada suhu kamar, kemudian sampel-sampel diambil pada setiap waktu perendaman yaitu: 1 jam, 2 jam, 4 jam, dan 5 jam. Setelah waktu perendaman tercapai, air yang menempel pada permukaan sampel diusap dengan kertas tisu secara hati hati dan ditimbang, berat untuk masing masing waktu perendaman dicatat sebagai $\mathrm{W}_{2}$. Sampel dengan berat $\mathrm{W}_{2}$ dikeringkan lagi dalam oven pada suhu $60^{\circ} \mathrm{C}$ hingga berat konstan, dicatat sebagai $\mathrm{W}_{3}$. Harga \% pengembangan diperoleh dari nilai rata-rata dalam lima (5) kali ulangan, digunakan neraca analitis dengan akurasi 0,0001 g pada percobaan ini. Persen pengembangan dihitung menurut Persamaan (2) dan Persamaan (3) [8]:

$$
\begin{aligned}
& \% \mathrm{DS}=\frac{\mathrm{W}_{2}-\mathrm{W}_{3}}{\mathrm{~W}_{2}} \times 100 \% \quad \ldots \ldots \ldots \ldots \ldots . . \\
& \text { Kelarutan gel }=\frac{\mathrm{W}_{1}-\mathrm{W}_{3}}{\mathrm{~W}_{1}} \times 100 \% \quad \ldots \ldots \ldots . .
\end{aligned}
$$

Percobaan kemampuan absorpsi hidrogel selulosa/PVA terhadap ion logam dilakukan pada 4 gelas beker masing masing dengan kapasitas $250 \mathrm{~m}$, digunakan larutan ion logam $\mathrm{pH}$ antara 2 hingga 7. Setiap gelas beker diisi $100 \mathrm{~mL}$ larutan ion logam pada konsentrasi 1500 ppm, dengan tahapan waktu pengujian yaitu; 2 jam, 10 jam, 16 jam dan 24 jam. Sebanyak $\pm 1,5$ gram sampel hidrogel selulosa/PVA, dari hasil terpilih yaitu dari $15 \%$, dosis $20 \mathrm{kGy}$ dengan perlakukan shaker dalam gerakan reciprocating selama 5 menit pada interval waktu 2 jam dengan kecepatan putar $300 \mathrm{rpm}$. Pada saat waktu pengujian telah tercapai, absorben dipisahkan dari larutan ion logam dengan cara penyaringan dengan kertas saring Whatman No. 42, kemudian sisa konsentrasi ion logam di dalam filtrat ditentukan menggunakan $A A S$ Shimadzu AA 6300. Larutan ion logam yang dibuat untuk $\mathrm{pH}$ rendah meliputi 2, 4 dan 5, sedangkan $\mathrm{pH}$ semi netral dengan $\mathrm{pH}$ sekitar 6,3.

Untuk mengetahui sifat topografi dari tampang lintang dan permukaan, dilakukan analisis Scanning Electron Microscopy (SEM Hitachi SU 3500) dari hidrogel selulosa/PVA dalam ukuran $2 \mathrm{~cm} \times 3 \mathrm{~cm}$ dikeringkan dengan freeze dryer, kemudian dilakukan analisis sifat morfologi di lnstansi P2F-LIPI, kawasan Puspiptek Serpong.

\section{HASIL DAN PEMBAHASAN}

Fraksi gel merupakan porsi gel yang berikatan silang pada matriks, dan tidak larut dalam air. Pada Tabel 1, terlihat bahwa dosis $10 \mathrm{kGy}$ semua gel larut dalam air, ini berarti tidak terjadi ikatan silang dari pasta selulosa/PVA untuk semua konsentrasi. Kemudian pada dosis $20 \mathrm{kGy}$ ikatan silang terjadi pada semua konsentrasi. Penggunaan dosis iradiasi yaitu $10 \mathrm{kGy}$ dan 20 kGy mengacu hasil penelitian sebelumnya, yang mengungkapkan bahwa penggunaan dosis iradiasi di atas 20 kGy terhadap PVA tidak disarankan, karena pada umumnya hasil proses degradasi lebih dominan dari pada ikatan silang [9]. Pembentukan polimer berikatan silang dapat terjadi melalui pembentukan radikal bebas. Menurut Hennink W.E. [10], radiolisis molekul air menghasilkan radikal hidroksil yang dapat menyerang rantai polimer PVA dengan pembentukan makroradikal. Melalui proses rekombinasi, makroradikal tersebut membentuk ikatan kovalen dan akhirnya terjadi struktur dengan ikatan silang. Di dalam matrik hidrogel selulosa/ PVA, komponen PVA dengan struktur berikatan silang melalui proses iradiasi terhadap larutan pasta PVA, diperlihatkan pada Gambar 3 [3].

\begin{tabular}{|c|c|c|}
\hline Konsentrasi ,\% & Warna & Sifat fisik \\
\hline 10 & transparan & lunak/lembek \\
\hline 15 & kuning pucat & agak kenyal/elastis \\
\hline 20 & kuning muda & kenyal/keras \\
\hline 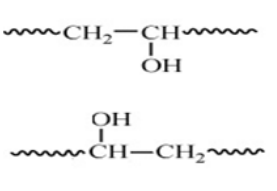 & $\stackrel{\gamma}{W^{M}}$ & 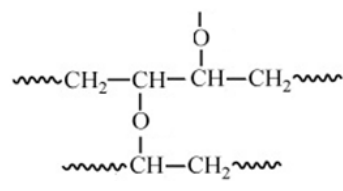 \\
\hline Pasta PVA & & Hidrogel PVA \\
\hline
\end{tabular}

Tabel 1. Persen fraksi gel hidrogel S/PVA pada dosis iradiasi 10 dan $20 \mathrm{kGy}$.

Gambar 3. Skema pembentukan ikatan silang pada hidrogel PVA iradiasi.

Fraksi gel serta daya swelling dipengaruhi oleh kepadatan makro radikal pada proses pembentukan gel, hal ini yang diduga terjadi pada dosis $20 \mathrm{kGy}$ di mana fraksi gel menurun dengan naiknya konsentrasi hidrogel selulosa/PVA. 
Hidrogel dengan stuktur berikatan silang mampu menyerap air, namun tidak larut dalam air. Proses masuknya air ke dalam matriks hidrogel berakibat pada pengembangan hidrogel itu sendiri. Ting Yang [11], mengungkapkan bahwa pada awal proses penyerapan, air berdifusi ke dalam jaringan secara kontinyu hingga mencapai kondisi setimbang, dengan pengembangan maksimum. Pasca fase kesetimbangan, jumlah air yang terserap menurun yang disebabkan oleh siklus pencairan gel.

Pada Gambar 4, terlihat persen pengembangan meningkat sebagai fungsi waktu dan mencapai kondisi maksimum setelah \pm 4 jam perendaman, untuk semua konsentrasi hidrogel selulosa/PVA yaitu $10 \%, 15 \%$ dan $20 \%$ dari dosis $20 \mathrm{kGy}$.

Pada Tabel 1, untuk dosis $20 \mathrm{kGy}$, persen pengembangan gel selulosa/PVA $10 \%$ lebih tinggi dibanding dengan konsentrasi 15 maupun $20 \%$, hal ini menurut Ling L. X. [12], suatu gel dengan porsi air yang besar mempunyai sifat hidrofilisitas yang tinggi, maka tinggi pula kemampuan dalam penyerapan air. Sedangkan hidrogel dengan konsentrasi gel lebih tinggi atau porsi air lebih rendah, mempunyai densitas lebih besar dari pada hal nya konsentrasi gel yang rendah, dan kemampuan dalam penyerapan air lebih rendah.

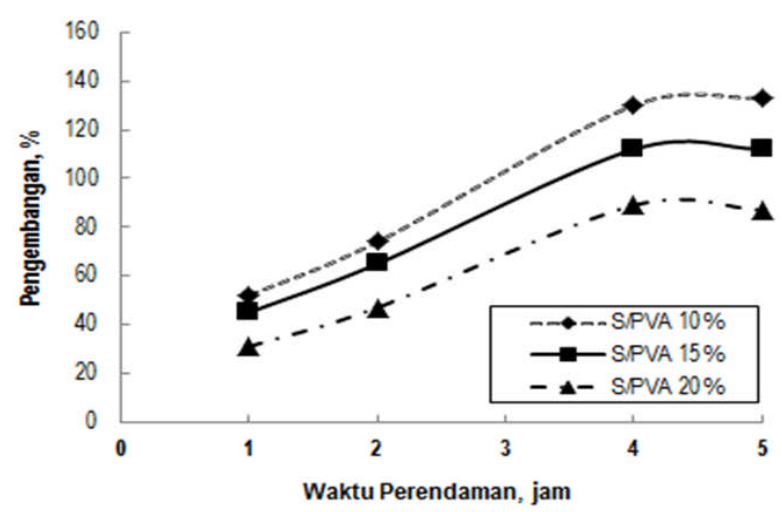

Gambar 4. Persen pengembangan hidrogel selulosa/PVA dosis $20 \mathrm{kGy}$ versus waktu perendaman.

Secara fisik hidrogel selulosa/PVA dosis $20 \mathrm{kGy}$ disajikan pada Tabel 2.

Tabel 2. Fisualisasi dan tekstur hidrogel selulosa/PVA .

\begin{tabular}{ccc}
\hline Konsentrasi $\%$ & Warna & Sifat fisik \\
\hline 10 & transparan & lunak/lembek \\
15 & kuning pucat & agak kenyal/elastis \\
20 & kuning muda & kenyal/keras \\
\hline
\end{tabular}

Dengan pertimbangan penampilan fisual serta sifat fisik pada Tabel 2, konsentrasi $15 \%$ dipilih sebagai sampel uji dalam penyerapan ion logam berat.

Analisis SEM, pada Gambar 5(a) menunjukkan suatu fisual dari permukaan yang halus dan homogen, terlihat gumpalan yang diduga berasal dari bentukan yang terjadi saat proses tuang-beku larutan pasta. Sementara pada foto SEM hidrogel selulosa/PVA
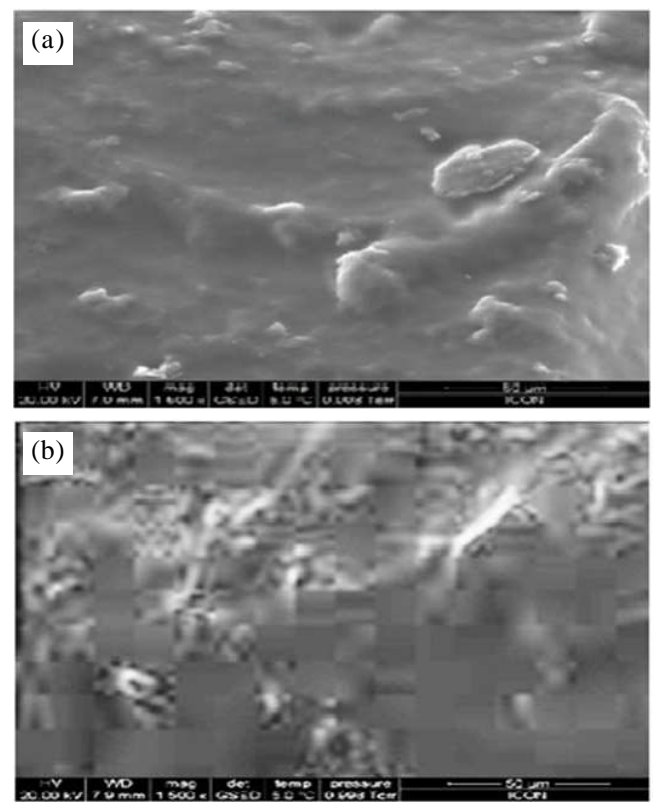

Gambar 5. (a). SEM hidrogel PVA $15 \%$, pembesaran 5000x, dan (b). SEM hidrogel selulosa/PVA (15\%, $20 \mathrm{kGy}$ ) pembesaran 5000x.

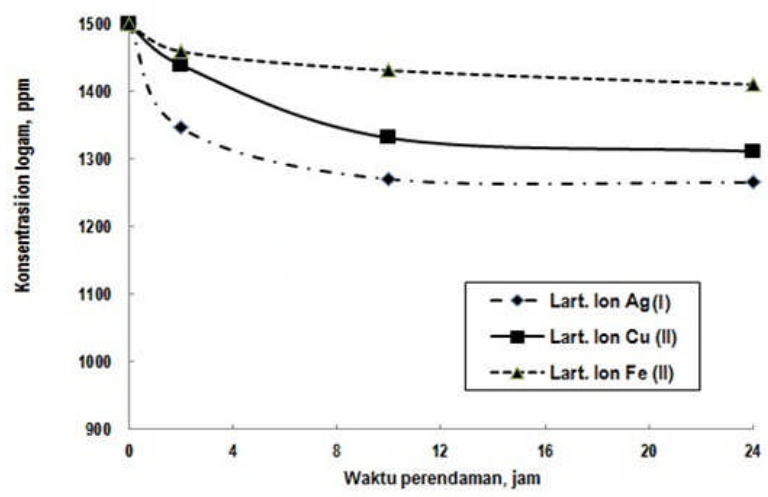

Gambar 6. Eliminasi ion $\mathrm{Ag}$ (I), $\mathrm{Cu}$ (II) dan $\mathrm{Fe}$ (II) ppm, oleh hidrogel selulosa/PVA, 15\% dosis $20 \mathrm{kGy}$.

(Gambar 5(b)), terlihat struktur permukaan yang mempunyai spot berwarna gelap, serta permukaan yang bergelombang. Bentuk alur gelombang pada permukaan diduga merupakan tampilan dari adanya entanglement atau lilitan rantai selulosa dalam matrik hidrogel selulosa/ PVA. Dari spot berwarna gelap diduga partikel serbuk selulosa yang didistribusikan secara merata dalam matriks, dengan struktur homogen, tanpa cacat makroskopik terlihat di antarmuka yang memungkinkan untuk difusi air, yang memungkin-kan untuk difusi air, sehingga dapat secara efektif digunakan sebagai absorben $[6,13]$.

Uji daya absorpsi ini digunakan hidrogel selulosa/ PVA konsentrasi $15 \%$, yang dipandang sebagai konsentrasi ideal, sementara pada $20 \%$ mempunyai densitas padatan yang tinggi menyebabkan daya absorpsi tidak optimal, sedangkan pada konsentrasi $10 \%$ absorpsi kurang stabil, di mana proses desorpsi lebih cepat terjadi karena sifat pengembangan yang 
besar [14]. Pada pengujian absorpsi ion logam $\mathrm{Cu}, \mathrm{Ag}$ dan Fe dengan hidrogel selulosa/PVA konsentrasi $15 \%$ untuk larutan dengan $\mathrm{pH}=2$ dan $\mathrm{pH}=4$, masing diperoleh absorpsi yang diperoleh 10 ppm dan 22 ppm (0,7 \% dan $1,4 \%)$. Secara signifikan fenomena ini tidak efisien dalam proses penyerapan ion logam, kehilangan ion logam bisa terjadi karena proses lain seperti filtrasi dan sebagainya. Sementara untuk $\mathrm{pH}=5$ daya absorbansi yang diperoleh pada kisaran 35 ppm.

Reem K [15], menyatakan bahwa larutan sampel ion-ion logam yang diabsorpsi pada suhu konstan (isothermal) dibuat dengan kondisi $\mathrm{pH} 6$ hingga 7 yang dimaksudkan untuk mencegah pengendapan pada saat proses absorpsi berlangsung. Secara umum dari ke 3 proses absorpsi berlangsung dengan urutan tahapan; yaitu pertama; penambahan ion terabsorpsi dengan waktu kontak, kedua; tercapai kondisi setimbang, dengan kapasitas absorpsi maksimum, dan akhirnya pelepasan kembali ion-ion terabsorpsi (desorpsi). Menurut Jamnongkan [1], model kinetika absorpsi tersebut termasuk isothermal Langmuir pseudo orde-2, dengan parameter absorpsi disajikan dalam Persamaan (4).

$$
\frac{d q}{d t}=\mathrm{k}_{2 .}\left\{\mathrm{q}_{\mathrm{e}}-\mathrm{q}\right\}^{2}
$$

\section{Dimana:}

$$
\begin{aligned}
\frac{d q}{d t}= & \text { Kecepatan absorpsi, } \\
\mathrm{k}_{2}= & \text { Konstanta kecepatan absorpsi pseudo orde } 2 \\
\mathrm{q}^{=} & \text {Jumlah konsentrasi ion logam terserap } \\
& \text { beberapa jam, serta } \\
\mathrm{q}_{\mathrm{e}}= & \text { Jumlah konsentrasi ion logam pada saat } \\
& \text { kondisi setimbang }
\end{aligned}
$$

Dari persamaan (4) dijabarkan ke dalam bentuk $\mathrm{q} / \mathrm{t}$ kemudian digunakan untuk menghitung beberapa parameter pada kurva dari gambar 6, diperoleh tabel sebagai berikut :

Dari Tabel 3 terlihat bahwa masing-masing ion logam mempunyai parameter yang berbeda pada interaksinya dengan hidrogel selulosa/PVA. Hal ini diduga disebabkan oleh faktor dari masing masing material yang saling berinteraksi yaitu karakter hidrogel selulosa/PVA dan ion logam. Menurut Ningmei W. dkk. [13 ] salah satu bentuk interaksi adalah difusi ion logam ke dalam ligand atom oksigen dari gugus hidroksil, serta interaksi elektrostatik ion logam dan gugus hidrofilik hidrogel selulosa/PVA.

Tabel 3. Kinetika absorpsi isothermal Langmuir pseudo orde-2 ion logam oleh hidrogel selulosa/PVA konsentrasi $15 \%$ pada suhu kamar.

\begin{tabular}{cccc}
\hline Parameter & $\mathrm{Ag}(\mathrm{I})$ & $\mathrm{Cu}(\mathrm{II})$ & $\mathrm{Fe}(\mathrm{II})$ \\
\hline $\mathrm{k}_{2 .}{ }_{2 .}(\mathrm{ppm} / \mathrm{jam})^{2}$ & 0,91 & 0,64 & 0,21 \\
$\mathrm{q}_{\mathrm{e}}(\mathrm{ppm})$ & 188 & 234 & 89 \\
$\mathrm{R}^{2}$ & 0,95 & 0,99 & 0,93 \\
\hline
\end{tabular}

\section{KESIMPULAN}

Hidrogel selulosa/PVA telah berhasil disintesis dengan teknik iradiasi sinar- $\gamma$, yang merupakan material ramah lingkungan, dari percobaan dapat berfungsi untuk mengeliminir ion logam dari larutan khususnya ion $\mathrm{Ag}$ (I), Cu (II) dan Fe (II). Absorpsi ion logam tersebut dilakukan pada suhu kamar dan diduga prosesnya mengikuti kinetika isothermal Langmuir pseudo orde- 2 .

\section{UCAPAN TERIMAKASIH}

Penulis mengucapkan terima kasih kepada Sdr. $\mathrm{R}$ Yoga Pramono, staf Balai IEI PAIR-BATAN atas bantuannya dalam proses iradiasi sampel.

\section{DAFTAR ACUAN}

[1]. T. Jamnongkan, A Wattanakornsiri, P. Wachirawongsakorn, and S. _Kaewpirom. "Effects of Crosslinking Degree of Poly(vinyl alcohol) Hydrogel in Aqueous Solution: Kinetics and Mechanism of Copper (II) Adsorption." Polym. Bul., vol. 71, pp. 1081-1100, 2014.

[2]. S. Reena, G. Neetu, A. Mishra, and G. Rajiv. "Heavy Metals and Living Systems." An overview, Indian J. of Pharm., vol. 43, pp. 246-253, 2011.

[3]. A.K. Elbadawy, C. Xin, M.S. Mohy Eldin and S.K. El-Refaie. "Crosslinked Poly(vinyl) Alcohol Hydrogel for Wound Dressing Applications : Review of Remarkably Blended Polymers." Arabian J. of Chem., vol. 8, pp. 1-14, 2015.

[4]. A.K. Elbadawy, C. Xin, M.S. Mohy Eldin and S.K. El-Refaie. "Crosslinked Poly(vinyl) Alcohol Hydrogel for Wound dressing applications : Review of remarkably blended polymers." Arabian J. of Chem., vol. 8, pp. 1-14, 2015.

[5]. H. Hosseinzadeh."Synthesis and Swelling Properties of a Poly(vinyl alcohol) Based Super Absorbing Hydrogel." Current Chem. Letters, vol. 2, pp. 153-158, 2013.

[6]. A. Suliwarno. "Hydrogel Based on Cross-linked Mthylcellulose Prepared by Electron Beam Irradiation for Wround Dressing Application." Indonesian J. of Chem. vol. 14, pp. 262-268, 2014.

[7]. N.M. Ranjha, A. Madni, A.A. Bakar, and H. Ahmad. "Preparation and Characterization of Isosorbide Mononitrate Hydrogels Obtained by Free-Radical Polymerization for Site-Specific Delivery.” Tropical J. of Pharm.. Res., vol. 13, pp. 1979-1985, 2014.

[8]. A. Bernal, I. Kuritka and P. Saha. "Poly(vinyl alcohol)-Poly(Vinyl Pyrrolidone) Blends: Preparation and Characterization for a Prospective Medical application." Math. Methods and Tech. in Eng. and Environ. Sci, pp. 432-434, 2011.

[9]. Erizal, P.P. Dian, A. Zuhelmi dan G.S. Sulistioso. "Modifikasi Fisiko Kimia Membrane Komposit 
Kitosan Poliviil Alkohol Hasil Casting Dengan Teknik Induksi Iradiasi Gamma.” J. Sains dan Mat. Indonesia, vol. 14, pp. 166-172, 2013.

[10]. W.E. Hennink and C.F. Van Nostrum. "Novel Crosslinking Methods to Design Hydrogels." Adv. Drug Delivery Rev., vol. 64, pp. 223-236, 2012.

[11]. T. Yang. "Mechanical and Swelling Properties of Hydrogels." Doctoral Thesis, KTH Chemical Science and Engineering, Swedia, 2012.

[12]. L. X. Ling, L. L. Cia, and W. Yan. "In-situ Crosslinked PVA/Organosilica Hybrid Membranes for Pervaporation Separations." J. of Memb. Sci., vol. 498, pp.263-275, 2016.

[13]. W. Ningmei and Z. Li. "Synthesis and Characterization of Poly(HEA/MALA) Hydrogel and Its Application in Removal of Heavy Metal Ions from Water." Chem. Eng. J. vol. 215-216, pp. 894-902, 2013.

[14]. K. Tsekova, D. Christova, D. Todorova, and S. Ivanova. "Removal of $\mathrm{Cu}$ (II), Co (II) and $\mathrm{Fe}$ (III) Ions from Ternary Solution by Free and Entrapped in PVA Hydrogel Biomass of Penicillium Cyclopium.” Biotechnology \& Biotechnological Equipment, vol. 25, pp. 41-46, 2014.

[15]. K .F. Reem and R.M. Riham. "Synthesis and Characterization of Carboxylmethyl Chitosan Nanogels for Swelling Studies and Antimicrobial Activity.” Molecules, vol. 18, pp. 190-203, 2013. 